\title{
Dissolution Profile Evaluation of Eight Brands of Metformin Hydrochloride Tablets Available in Jimma, Southwest Ethiopia
}

\author{
Belachew Umeta' \\ Anbessa Bekele' \\ Tesfaye Mohammed (D) ${ }^{1,2}$ \\ Markos Duguma ${ }^{2}$ \\ Henok Teshome ${ }^{2}$ \\ Yimer Mekonnen (iD) ${ }^{1,2}$ \\ 'Department of Pharmaceutical Sciences, \\ School of Pharmacy, Institute of Health, \\ Jimma University, Jimma, Oromia, \\ Ethiopia; ${ }^{2}$ Jimma University Laboratory of \\ Drug Quality (JULaDQ), Jimma \\ University, Jimma, Oromia, Ethiopia
}

Correspondence: Belachew Umeta Department of Pharmaceutical Sciences, School of Pharmacy, Institute of Health, Jimma University, PO Box 378, Jimma, Oromia, Ethiopia

Tel +251901649597

Email belachew.umeta@ju.edu.et
Background: Dissolution is the critical quality control parameter and used to predict an in vivo oral bioavailability, and it is used to support bio-waiver.

Aim: To evaluate and compare the dissolution profile of eight brands of metformin HCL $500 \mathrm{mg}$ tablets available in Jimma town, Southwest Ethiopia.

Methods: The study was conducted in Jimma town, Ethiopia. Eight (seven brands and one comparator) metformin HCL $500 \mathrm{mg}$ tablets were included. The dissolution study was conducted as per United States Pharmacopeia, and the dissolution profile was compared by one-way ANOVA, model-dependent and model-independent approaches.

Results: All of the included tablet brands complied with single-point dissolution study specification. Statistical comparisons of the dissolution profile by one-way ANOVA revealed that all brands had similar dissolution profiles $(p=0.89)$. All of the brands had a similarity factor $\left(f_{2}\right)>50 \%$ and the difference factor $\left(f_{1}\right)<15$. The entire brands followed the Weibull curve approach (the highest coefficient of determination and lowest Akaike Information Criteria) for the release of an active pharmaceutical ingredient.

Conclusion: All of the brands complied with single point dissolution study and all of them could be used interchangeably with the innovator drug. All brands followed the Weibull method for the release of the drug substance.

Keywords: dissolution, Jimma, metformin hydrochloride, biopharmaceutical classification

\section{Introduction}

According to a WHO 2016 report, diabetes mellitus is commonly classified as Type 1 or Type 2 diabetes. Type 2 diabetes was the major cause of total diabetes prevalence and affects every population. The number of patients with diabetes mellitus is increasing. Accordingly the number of adult patients was 422 million in 2014 worldwide. The prevalence was $4.7 \%$ in adults in 1980 which becomes $8.5 \%$ in the year 2014, and the rise was high in low- and middle-income countries. ${ }^{1}$ Besides, according to an International Diabetes Federation projection there will be 552 million diabetic patients by $2030^{2}$ and most of them will be living in low- and middle-income countries. Each year four million deaths in the world are attributed to diabetes mellitus, and in 2017 the annual expenditure was 850 billion US dollars. Unless otherwise halted the socioeconomic consequences will be huge. ${ }^{3-5}$ However, the World Health Organization reported that $30 \%$ of drugs sold in Africa were poor quality. This fact might be attributed to weak regulatory systems and/or limited resources. 


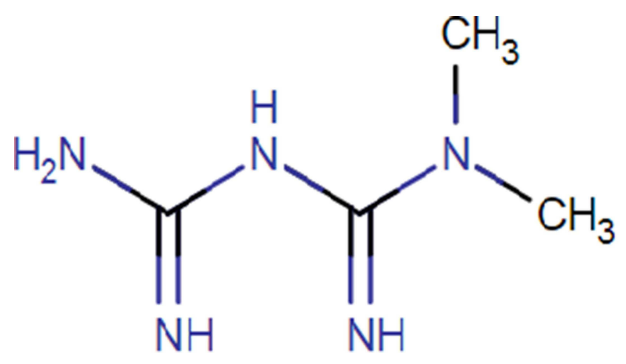

Figure I Chemical structure of metformin hydrochloride.

Chemically, metformin HCL was N, N-dimethyl-imido -dicarbonimidic diamide hydrochloride (Figure 1). The molecular weight of metformin is $129 \mathrm{Da}$ and it has low solubility in lipid media. Due to this, the ability of the drug to pass the cell membrane is low. ${ }^{6}$

As per the Biopharmaceutics Classification System (BCS), it is class III drug. ${ }^{7}$ Therefore, permeability is the rate-limiting step in drug absorption. Dissolution is the critical quality control parameter for drugs as it has direct impact on absorption. Fast dissolution is required to enhance contact time of the dissolved drug with absorption mucosa. So, the duration of dissolution should be hardline for such drugs. In vitro in vivo correlation (IVIVC) serves as a surrogate for in vivo bioavailability and to support bio-waivers. IVIVCs could also be employed to establish dissolution specifications and to support and/or validate the use of dissolution methods. ${ }^{8,9}$ Dissolution as a quality control tool for forecasting in vivo performance of a drug product is significantly enhanced if an in vitro-in vivo relationship is established. The in vitro test serves as a tool to differentiate passable and impassable drug products. Passable products are bioequivalent in terms of in vivo performance and vice versa. ${ }^{10}$ The absorption of drugs after oral administration depends on various factors from which the release of the drug substance from the dosage form, its dissolution in physiological conditions, and its permeability through the gastrointestinal tract, and the tests are mainly used to assure the quality of the pharmaceutical product. Different methods for comparisons of dissolution profiles of different tablets are suggested by SUPAC-IR ${ }^{10}$ from those, statistical analyses by one-way analysis of variance, model-dependent and model-independent parameters are common.

Even though there are different brands of drugs introduced into the world pharmaceutical market to improve public health outcome, the proportion of poor quality drugs are increasing proportionally worldwide. The study done in Albania to check the interchangeability of three brands of metformin HCL indicated that two of the brands could be used interchangeably. ${ }^{11}$ Another study done in Asia (Qatar) to assess bioequivalence and interchangeability of 10 different brands of metformin hydrochloride revealed that only six of the brands could be used interchangeably with the comparator. ${ }^{12}$ Similar to other parts of the world, the African continent as a whole is also facing a great challenge in the quality of medicines. The study done in Nigeria for comparative evaluation of the physicochemical properties of some commercially available brands of metformin HCL tablets on eight different brands showed that only four of the brands are bioequivalent and can be used interchangeably. ${ }^{13}$ Therefore, the aim of the study was to evaluate and compare dissolution profile of different brands of metformin hydrochloride tablets available in Jimma town.

\section{Materials and Methods}

\section{Study Setting and Period}

The study was conducted in Jimma town. The town is located $357 \mathrm{~km}$ southwest of Addis Ababa, the capital of Ethiopia. All private and public pharmacies available in the town were included in the study. The town is used as a commercial hub for the transaction of pharmaceuticals in the southwest region of the country. According to Ethiopian pharmaceutical supply agency of Jimma branch there are, eight wholesales, 33 drug vendors, four public drug shops in health centers, 23 private pharmacies, three public hospitals, and three private hospitals in the town. The laboratory work was done in Jimma University Laboratory of Drug Quality (JULaDQ). All brands included in the study were within their shelf life at the time of the study (Table 1). The work was conducted from July to August 2019.

\section{Instruments}

Analytical Balance (Mettler Toledo, Switzerland), RC-6D Dissolution Apparatus (Apparatus 2; Tian Jin Optical Instruments, China), UV-Vis Spectrophotometer (Cecil Instruments, UK), and Water Purification System (Thermo Scientific, Model-7143, USA) were used for the study.

\section{Chemical and Reagents}

Distilled water, sodium hydroxide (BDG Laboratory Supplies, Purity $=97.5 \%$ ), potassium dihydrogen orthophosphate (Techno Pharm Chem, Bahadurgarh, Purity $=99$ 
Table I General Characteristics of Brands Included in the Study, 2019

\begin{tabular}{|l|c|c|}
\hline Brands code & Man. Date & Exp. date \\
\hline MT008* & $10 / 2018$ & $09 / 2023$ \\
\hline MT004 & $07 / 2018$ & $06 / 2023$ \\
\hline MT00I & $12 / 2018$ & $09 / 2021$ \\
\hline MT007 & $08 / 2018$ & $08 / 2022$ \\
\hline MT005 & $06 / 2018$ & $06 / 2021$ \\
\hline MT006 & $07 / 2018$ & $07 / 2021$ \\
\hline MT002 & $06 / 2018$ & $06 / 2023$ \\
\hline MT003 & $12 / 2017$ & $12 / 2020$ \\
\hline
\end{tabular}

Note: ${ }^{\mathrm{a} C o m p a r a t o r}$.

$101 \%$, India) were used. The working standard of metformin hydrochloride was donated by the Ethiopian Food and Drug Administration Authority (EFDA).

\section{Sampling Technique and Sample Collection}

All available eight brands of metformin HCL $500 \mathrm{mg}$ tablets were purchased from private and public drug retail outlets available in Jimma town by trained mystery shoppers. Since Ethiopia is one of the countries with weak medicine regulations, there might be outlets selling expired or unregistered medicines, which may make outlet staff suspicious and anxious about the investigations. Besides, in resource-poor countries, the medicine market is heavily segmented with different people of different spending power, and the mystery shopper approach was used to overcome this issue. The mystery shoppers where instructed simply to state that they are diabetic patients travelling somewhere and running out of their medication. The aim of the study was blinded for mystery shoppers and they were only instructed to collect the samples. The relevant information collected was the name of drug substance, country of origin, manufacturing company, expiry date, manufacturing date, and batch/lot number. Guidelines for field surveys of the quality of medicines proposed by Newton et al were used for sampling strategy. ${ }^{14}$ Only one brand was purchased from each outlet. The samples were kept in their original package, transported to Jimma University laboratory of drug quality (JuLaDQ), and stored under room temperature until the analysis. General characteristics of brands included in the study are presented in Table 1.

\section{Dissolution Test Calibration Curve}

A stock solution was prepared by dissolving $100 \mathrm{mg}$ of metformin hydrochloride USP RS in $100 \mathrm{~mL}$ of phosphate buffer ( $\mathrm{pH}$ 6.8). From the stock solution, six concentration levels $(6,7,8,9,10$, and $12 \mu \mathrm{g} / \mathrm{mL})$ were prepared with phosphate buffer. Then, the absorbance was determined spectrophotometrically at a wavelength of $233 \mathrm{~nm}$ and plotted against the six concentration levels to draw the calibration curve.

\section{Dissolution Profile}

The test was conducted as outlined on the USP monograph on eight tablets of each brand using USP Apparatus II operated at $50 \mathrm{rpm}$. The dissolution medium was $1000 \mathrm{~mL}$ phosphate buffer ( $\mathrm{PH}$ 6.8) maintained at $37^{\circ} \mathrm{C} \pm 0.5^{\circ} \mathrm{C}$. USP 2015 specifies that at a single time of $30 \mathrm{~min}, 80 \%$ of the drug substance needs to be dissolved. $^{15}$ Samples of $10 \mathrm{~mL}$ was withdrawn at 5 , 15 , 30, and 45 minutes, and a fresh $10 \mathrm{~mL}$ dissolution medium was used to replace the withdrawn sample after each sampling, and then, the withdrawn samples filtered. After filtration and appropriate dilution $(100 \times)$, the absorbance were measured by UV-visible spectrophotometer at a wavelength of $233 \mathrm{~nm}$. Finally, the concentration was determined from the calibration curve of the standard solution having a known concentration of metformin hydrochloride RS in the same medium, and the percentage drug release was calculated each time. All of the experiments were done in triplicate.

\section{Data Analysis}

Microsoft Excel 2010 and SPSS version 20 software programs were used for statistical analysis. $p<0.05$ were considered as statistically significant, and one-way ANOVA was carried out for comparison of the dissolution profile of metformin hydrochloride tablets. The dissolution profile of those tablets was also compared by the model-dependent and model-independent methods (Table 2).

Table 2: Model dependent and model independent parameters used to compare metformin hydrochloride tablet brands included in the study. 
Table 2 Model dependent and model independent parameters used to compare metformin hydrochloride tablet brands included in the stud

\begin{tabular}{|c|c|}
\hline Model Dependent & Model Independent \\
\hline Zero order $\mathrm{Q}=\mathrm{K} . \mathrm{t}+\mathrm{Q}_{0}$ & $\begin{array}{l}\mathrm{f}_{1}=\left\{\left[\frac{\sum_{\mathrm{t}=1}^{\mathrm{n}} \mid \mathrm{R}_{\mathrm{t}}-\mathrm{T}_{\mathrm{t}}}{\sum_{\mathrm{t}=1} \mathrm{R}_{\mathrm{t}}}\right]\right\} 100 \\
\mathrm{f}_{2}=50 \log \left\{\left[+\left(\frac{1}{\mathrm{n}}\right) \sum_{\mathrm{t}=1}^{\mathrm{n}}\left(\mathrm{R}_{\mathrm{t}}-\mathrm{T}_{\mathrm{t}}\right)^{2}\right]^{0.5} 100\right\}\end{array}$ \\
\hline First order $\mathrm{Q}=\mathrm{Q}_{\mathrm{O}} \mathrm{e}^{\mathrm{k}-\mathrm{t}}$ & $\mathrm{DE}=\frac{\int_{t}^{t} \mathrm{Qdt}}{\mathrm{Q}_{100 x t}} \times 100$ \\
\hline Second order $\frac{1}{\mathrm{Q}}=\mathrm{K} \cdot \mathrm{t}+\frac{1}{\mathrm{Q}_{\mathrm{o}}}$ & $\mathrm{MDT}=\frac{\sum_{\mathrm{j=1}}^{\mathrm{n}} \mathrm{t}_{\mathrm{j}}^{\mathrm{t} \mathrm{AV}} \mathrm{X} \Delta \mathrm{Q}_{\mathrm{j}}}{\sum_{\mathrm{j}=1}^{\mathrm{n}} \Delta \mathrm{Q}_{\mathrm{j}}}$ \\
\hline Third order $\frac{1}{\mathrm{Q}^{2}}=\mathrm{K} \cdot \mathrm{t}+\frac{1}{\mathrm{Q}_{O}^{2}}$ & \\
\hline Hixson-Crowell model $\mathrm{Q}^{\frac{1}{3}}=K \cdot\left(-T_{L A G}\right)+Q O^{\frac{1}{3}}$ & \\
\hline Higuchi model $\mathrm{Q}=\mathrm{K} \cdot \sqrt{ } \mathrm{t}$ & \\
\hline Weibull model $\mathrm{m}=1-\exp \left[\frac{-(\mathrm{t})^{\mathrm{b}}}{a}\right]$ & \\
\hline $\begin{array}{l}\text { Best model criteria } \\
\mathrm{R}^{2}=\frac{\left[\mathrm{N} \cdot \sum_{\mathrm{i}=1}^{\mathrm{N}}\left(\mathrm{X}_{\mathrm{i}} \cdot \mathrm{Y}_{\mathrm{i}}\right)-\sum_{\mathrm{i}=1}^{\mathrm{N}} \mathrm{X}_{\mathrm{I}} \sum_{\mathrm{i}=1}^{\mathrm{N}} \mathrm{Y}_{\mathrm{i}}\right]^{2}}{\left[\mathrm{~N} \cdot \sum_{\mathrm{i}=1}^{\mathrm{N}} \mathrm{X}_{\mathrm{i}}^{2}-\left(\sum_{\mathrm{i}=1}^{\mathrm{N}} \mathrm{X}_{\mathrm{i}}\right)^{2}\right] \cdot\left[\mathrm{N} \cdot \sum_{\mathrm{i}=1}^{\mathrm{N}} \mathrm{Y}_{\mathrm{i}}{ }^{2}-\left(\sum_{\mathrm{i}=1}^{\mathrm{N}} \mathrm{Y}_{\mathrm{i}}\right)^{2}\right]} \mathrm{AIC}=2 \mathrm{~K}+\mathrm{N} \cdot\left[\ln \left(\sum_{\mathrm{i}=1}^{\mathrm{N}}\left(\mathrm{Y}_{\mathrm{i}}-\widehat{\mathrm{Y}}_{\mathrm{i}}\right)^{2}\right)\right]\end{array}$ & \\
\hline $\begin{array}{l}\text { Where, } \\
Q_{0} \text { is the initial amount of drug substance } \\
Q \text { is the amount of drug substance released at time, } t \\
t \text { is time } \\
K \text { is the rate constant } \\
T_{L A G} \text { is lag time } \\
m \text { is the amount of drug substance dissolved at time, } t \\
a \text { is time constant } \\
b \text { is shape parameter } \\
R^{2} \text { is coefficient of determination } \\
Y_{i} \text { is observed value } \\
i \text { is data point } \\
N \text { is number of data points } \\
A I C \text { is an Akaike information criterion } \\
K \text { is rate constant, } \\
Y_{i} \text { is observed values } \\
N \text { is number of data points }\end{array}$ & $\begin{array}{l}\text { Where, } \\
f_{1} \text { is difference factor } \\
f_{2} \text { is similarity factor } \\
n \text { is the number of time points } \\
R_{t} \text { is the dissolution value of the reference at time, } t \\
T t \text { is the dissolution value of the test drug at time, } t \\
D E \text { is dissolution efficiency } \\
M D T \text { is mean dissolution time } \\
\Delta Q=Q(t)-Q(t-1), t_{j}^{A V}=\left(t_{i}+t_{i-1}\right) / 2 \text {, and } n \text { is amount of } \\
\text { time points }\end{array}$ \\
\hline
\end{tabular}

\section{Result}

\section{Calibration Curve}

As shown on the calibration curve (Figure 2), a linear regression equation was $\mathrm{Y}=0.0769 \mathrm{X}+0.0535$ with $\mathrm{r}^{2}=0.9987$, where " $\mathrm{Y}$ " is the absorbance, and " $\mathrm{X}$ " is the concentration in $\mu \mathrm{g} / \mathrm{mL}$. By using this equation, the percentage drug substance released at times of 5, 15, 30, and 45 min were calculated.

\section{Dissolution Study}

At pharmacopeia time in $30 \mathrm{~min}$, all of tablet released the recommended amount of drug substance as shown in Figure 3.

\section{Mean Dissolution Time}

The mean dissolution time for each brand included in the study is shown in Table 3. MT003 and MT006 had the highest and lowest mean dissolution time, respectively. 


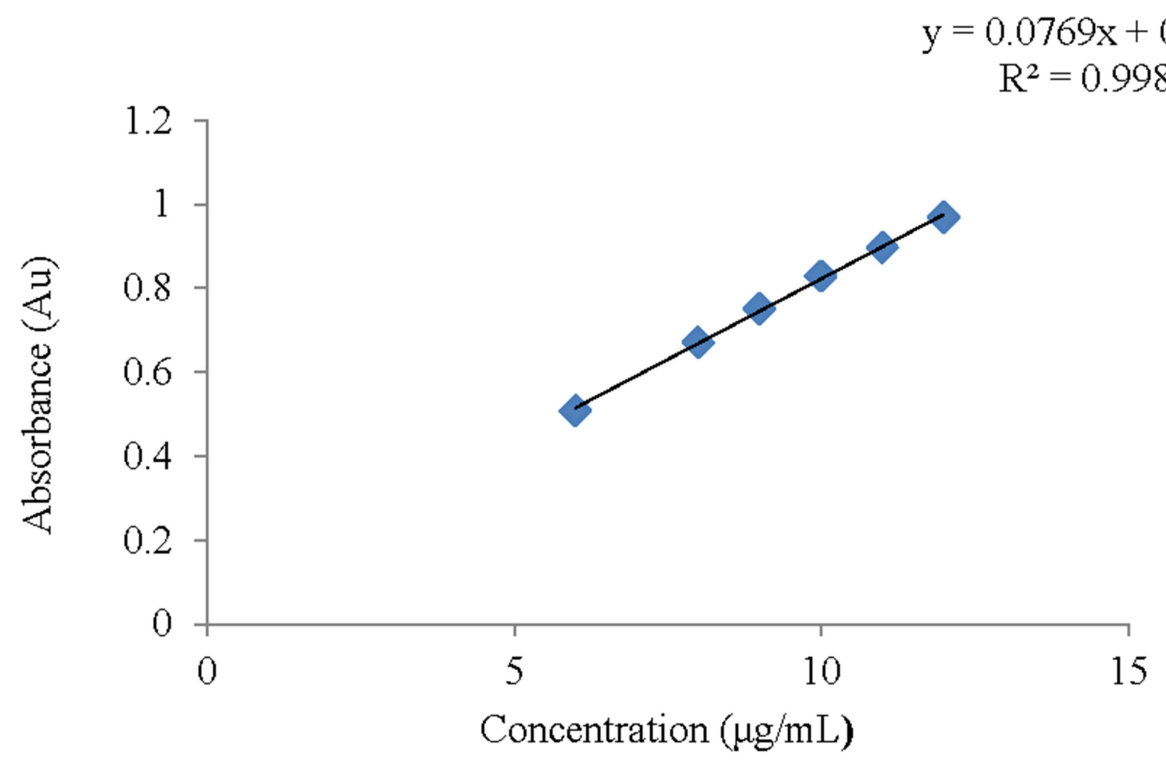

Figure 2 Calibration curve for dissolution study of metformin hydrochloride $500 \mathrm{mg}$ tablets tested, 2019/2020.

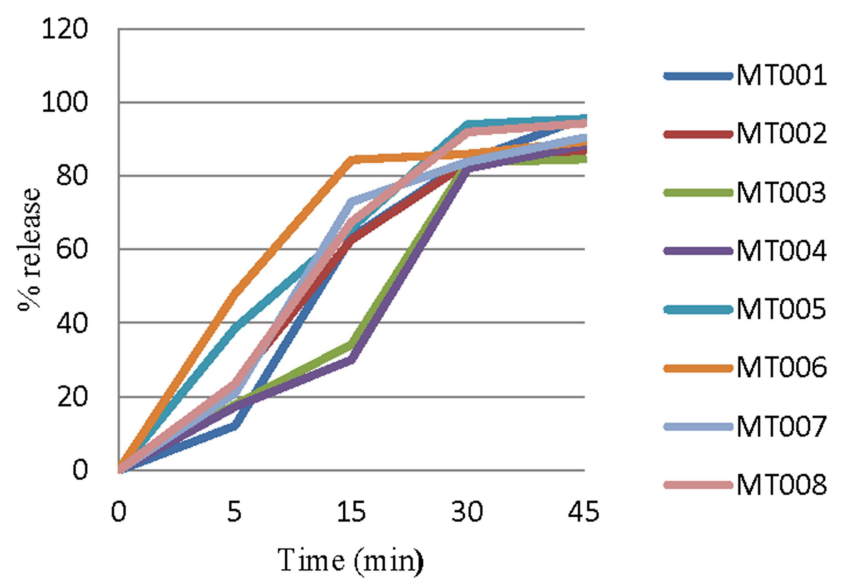

Figure 3 Dissolution profile (mean, $\mathrm{n}=6$ ) of metformin hydrochloride $500 \mathrm{mg}$ tablets included in the study, 2019.

\section{Comparison of Dissolution Profile}

Statistically, all of the tested drugs had a similar dissolution profile (Table 3). As per the fit factors, All brands had a similarity factor $\left(\mathrm{f}_{2}\right)$ of greater than $50 \%$ and difference factor $\left(f_{1}\right)$ of $<15$. All of them had a difference in dissolution efficiency of within $\pm 10 \%$ except MT003 and MT004 (Table 3).

\section{Model-dependent Methods}

The model-dependent approach showed that all of tested metformin HCL tablets were best explained by Weibull curve with highest determination coefficient $\left(\mathrm{R}^{2}\right)$ and lower AIC as shown in Table 4.

\section{Discussion}

Dissolution of a drug is an essential aspect for drug evaluation, and it is one of the most important control tests for assuring product uniformity and batch-to-batch equivalence. According to the present study, all the brands released the necessary amount of drug substance in 30 min as outlined on USP ( $>80 \%$ of drug substance needs to be dissolved). ${ }^{15}$ Even though statistical equivalence does not guarantee biopharmaceutical equivalence, all of the brands had a similar dissolution profile $(p>0.05)$. However, to study the dissolution profile of different brands $10 \mathrm{~mL}$ of samples were taken at $5,15,30$, and $45 \mathrm{~min}$ (Figure 3) and there is a difference in dissolution profile of different brands. This difference might be attributed to difference in excipients used and difference in manufacturing process used by various manufacturing industries.

Mean dissolution time (MDT) characterizes the drug substance release from the dosage form and the retarding efficiency of the polymer. A higher value of mean dissolution time indicates the lowest rate of drug release from the dosage form. This in turn leads to the slow onset of action and higher drug-retaining ability of the polymer and vice versa. ${ }^{16}$ Accordingly, MT003 had the highest mean dissolution time. Therefore, the drug might be characterized by slow release of the drug from the dosage form and longer onset of action. However, MT006 had the minimum mean dissolution time, and so it may require a short time to dissolve, and might have a fast onset of action. This difference in mean dissolution time might be related to difference in manufacturing processes. 
Table 3 Comparisons of Dissolution Profile of Metformin Hydrochloride $500 \mathrm{mg}$ Tablets Included in the Study by Model Independent Parameters, Jimma Town, $2019(n=3)$

\begin{tabular}{|c|c|c|c|c|c|c|}
\hline \multirow[t]{2}{*}{ Brands code } & \multicolumn{2}{|c|}{$\begin{array}{l}\text { Model Independent } \\
\text { Approach }\end{array}$} & \multirow[t]{2}{*}{$\begin{array}{l}\text { Dissolution } \\
\text { Efficiency (\%) }\end{array}$} & \multirow{2}{*}{$\begin{array}{l}\text { Difference of Dissolution } \\
\text { Efficiency (Innovator- } \\
\text { Tested Brands) }\end{array}$} & \multirow[t]{2}{*}{ MDT } & \multirow[t]{2}{*}{$p$-value } \\
\hline & $\mathbf{f}_{\mathbf{I}}$ & $\mathbf{f}_{2}$ & & & & \\
\hline MT00I & 7.80 & 60.88 & 63.60 & 5.42 & 15.13 & 0.89 \\
\hline MT002 & 8.35 & 69.70 & 63.70 & 5.32 & 12.95 & \\
\hline MT003 & 8.32 & 69.26 & 54.59 & 14.53 & 18.82 & \\
\hline MT004 & 9.88 & 97.67 & 53.30 & 15.72 & 17.84 & \\
\hline MT005 & 2.08 & 4.33 & 72.01 & -2.99 & 11.11 & \\
\hline МT006 & 6.14 & 37.67 & 74.99 & -5.97 & 7.21 & \\
\hline MT007 & 8.06 & 65.00 & 66.79 & 2.23 & 11.75 & \\
\hline MT008 ${ }^{\mathrm{a}}$ & - & - & 69.02 & - & 12.07 & \\
\hline
\end{tabular}

Note: ${ }^{2}$ Comparator.

Abbreviations: $M D T$, mean dissolution time; $\mathrm{f}_{\mathrm{l}}$, difference factor; $\mathrm{f}_{2}$, similarity factor.

Table 4 Comparisons of Dissolution Profile of Metformin HCL 500 mg Tablets Included in the Study by Model Dependent Approach; Jimma Town, 2019

\begin{tabular}{|c|c|c|c|c|c|c|c|c|c|}
\hline \multirow[t]{2}{*}{ Model dependent parameters } & \multicolumn{9}{|c|}{ Tested tablet brands code } \\
\hline & Parameters & MT00I & MT002 & MT003 & MT004 & MT005 & MT006 & MT007 & MT008 \\
\hline \multirow[t]{2}{*}{ zero } & $R^{2}$ & 0.8398 & 0.8352 & 0.8819 & 0.9096 & 0.8663 & 0.6123 & 0.7275 & 0.8048 \\
\hline & AIC & 29.9581 & 27.8774 & 28.1026 & 27.448 & 26.705 & 27.095 & 30.817 & 29.794 \\
\hline \multirow[t]{2}{*}{ First } & $R^{2}$ & 0.6822 & 0.7255 & 0.8711 & 0.8999 & 0.8166 & 0.5876 & 0.6351 & 0.7073 \\
\hline & AIC & 35.2891 & 31.0839 & 32.2301 & 31.911 & 29.308 & 29.113 & 33.669 & 33.156 \\
\hline \multirow[t]{2}{*}{ Second } & $\mathrm{R}^{2}$ & 0.5723 & 0.6321 & 0.8017 & 0.8453 & 0.7518 & $0.567 \mid$ & 0.5703 & 0.6194 \\
\hline & AIC & 55.166 & 38.4199 & 43.4612 & 44.372 & 33.225 & 30.485 & 42.763 & 41.689 \\
\hline \multirow[t]{2}{*}{ Third } & $R^{2}$ & 0.5274 & 0.5710 & 0.7013 & 0.7508 & 0.6855 & 0.5508 & 0.5350 & 0.5622 \\
\hline & AIC & 42.166 & 40.48558 & 40.5107 & 40.779 & 45.504 & 33.021 & 41.286 & 41.397 \\
\hline \multirow[t]{2}{*}{ Hixson-Crowell } & $R^{2}$ & 0.7334 & 0.7619 & 0.8803 & 0.9064 & 0.8354 & 0.5954 & 0.6635 & 0.7406 \\
\hline & AIC & 32.9672 & 29.7878 & 30.5536 & 30.052 & 28.349 & 28.792 & 32.418 & 31.775 \\
\hline \multirow[t]{2}{*}{ Higuchi } & $R^{2}$ & 0.7154 & 0.9169 & 0.7583 & 0.7158 & $0.894 \mid$ & -0.1546 & 0.8150 & 0.8809 \\
\hline & AIC & 32.2569 & 25.1366 & 30.9685 & 32.030 & 25.774 & 32.688 & 29.267 & 27.818 \\
\hline \multirow[t]{2}{*}{ Weibull } & $R^{2}$ & 0.9759 & $0.977 \mid$ & 0.9308 & 0.9190 & 0.9718 & 0.8712 & 0.9334 & 0.9792 \\
\hline & $\mathrm{AIC}$ & 23.8897 & 20.3587 & 26.0032 & 26.5406 & 19.388 & 23.259 & 25.601 & 18.618 \\
\hline
\end{tabular}

Abbreviations: $\mathrm{R}^{2}$, determination coefficient; AIC, Akaike Information Criteria.

To ascertain the interchangeability, the modelindependent approach of similarity, and difference factor was used. To be interchangeable, the similarity factor should be $50-100$, and the difference factor should be less than $15 .^{10}$ Accordingly, all of the brands can be used interchangeably with the innovator as they have a similarity factor of $>50$ and difference factor of $<15$. According to Anderson et al, for two drugs to be used interchangeably the difference of dissolution efficiency of innovator and tested drugs should be comparable with $\pm 10 \%$ and vice versa. ${ }^{17}$ Thereupon, except MT003 all of the brands have difference in DE of within $\pm 10 \%$. This 
report is different from a study in Saudi Arabia on six different brands of metformin hydrochloride and reported that five of the brands can be used interchangeably with the innovator drug. ${ }^{18}$ Another study conducted in Jordan revealed that from five brands of metformin hydrochloride, three of them were not bioequivalent with the innovator drug, and might not be used interchangeably in clinical practice. ${ }^{19}$ The study conducted on 10 brands of metformin HCL in Saudi Arabia in 2020 reported that nine of the brands were bioequivalent. $^{20}$ Whereas a study from Nigeria on eight brands of metformin HCL on the market reported that only four of them are interchangeable in clinical practice. ${ }^{13}$ This discrepancy might be due to the inclusion of different types of brands for the study. The model-dependent methods showed that all of the brands followed the Weibull curve method for the release of the drug substance.

\section{Conclusion and Recommendations}

As per the present study, all of the brands complied with single point USP pharmacopoeia specification for the release of the drug substance. Depending on fit factors and difference of dissolution efficiency criteria; all of the brands can be used interchangeably with the innovator drug. The model-dependent approach revealed that all of them followed the Weibull curve approach.

\section{Acknowledgments}

The authors acknowledge Jimma University for funding this work. We would also like to thank Jimma University Laboratory of Drug Quality for permitting the laboratory facilities, and the Ethiopian Food and Drug Administration Authority (EFDA) for kind alms of metformin hydrochloride working standard.

\section{Disclosure}

The authors report no conflicts of interest in this work.

\section{References}

1. Roglic G. WHO Global report on diabetes: a summary. Int J Noncommun Dis. 2016;1(1):3. doi:10.4103/2468-8827.184853

2. Whiting DR, Guariguata L, Weil C, Shaw J. IDF diabetes atlas: global estimates of the prevalence of diabetes for 2011 and 2030. Diabetes Res Clin Pract. 2011;94(3):311-321. doi:10.1016/j.diabres.2011.10.029
3. World Health Organization. World Malaria Report 2015. World Health Organization; 2016.

4. Forouhi NG, Wareham NJ. Epidemiology of diabetes. Medicine (Abingdon). 2014;42(12):698-702. doi:10.1016/j.mpmed.2014.09.007

5. World Health Organization. Classification of diabetes mellitus. World Health Organization; 2019. Available from: https://www.who.int/pub lications/i/item/classification-of-diabetes-mellitus.

6. Petrovick GF. Type 2 diabetes mellitus and metformin hydrochloride usage: a short. J Pharmacol. 2018;2(2):5.

7. Patel A, Ray S, Thakur RA. In vitro evaluation and optimization of controlled release floating drug delivery system of metformin hydrochloride. Daru J Pharm Sci. 2006;14(2):57-64.

8. Emami J. In vitro-in vivo correlation: from theory to applications. J Pharm Sci. 2006;9(2):169-189.

9. Amidon GL, Lennernäs H, Shah VP, Crison JR. A theoretical basis for a biopharmaceutic drug classification: the correlation of in vitro drug product dissolution and in vivo bioavailability. Pharm Res. 1995;12(3):413-420. doi:10.1023/A:1016212804288

10. Food and Drug Administration. Guidance for Industry: Dissolution Testing of Immediate Release Solid Oral Dosage Forms. Center for Drug Evaluation and Research (CDER), US Department of Health and Human Services; 1997.

11. Troja E, Deda L, Boçari G, Pëllumbi A. A comparative study of three formulations of metformin tablets available on the Albanian market. AJMHS. 2015;46(2):46-55.

12. Younes H, Al-Hasan N, Eldos K, Arakkal S. Assessment of quality control parameters and in vitro bioequivalence/interchangeability of multisourced marketed metformin hydrochloride tablets. Qatar Med J. 2017;2017(3):4. doi:10.5339/qmj.2017.HMCCPC.4

13. Akinleye MO, Adelaja IA, Odulaja JO. Comparative evaluation of physicochemical properties of some commercially available brands of metformin $\mathrm{HCl}$ tablets in Lagos, Nigeria. J Appl Pharm Sci. 2012;02(02):41-44.

14. Newton PN, Lee SJ, Goodman C, et al. Guidelines for field surveys of the quality of medicines: a proposal. PLoS Med. 2009;6(3): e1000052. doi:10.1371/journal.pmed.1000052

15. US Pharmacopoeia National Formulary. USP 38/NF33, United States Pharmacopoeial Convention. Rockville, MD, USA: US Pharmacopoeia National Formulary; 2015.

16. Das U, Halder S, Kabir AK, Rashid HO, Rouf AS. Development and in vitro evaluation of sustained release matrix tablets of indapamide from Methoce ${ }^{\circledR}$ K15 MCR and K100 LVCR. Dhaka Univ J Pharm Sci. 2011;10(2):87-92. doi:10.3329/dujps.v10i2.11785

17. Anderson NH, Bauer M, Boussac N, Khan-Malek R, Munden P, Sardaro M. An evaluation of fit factors and dissolution efficiency for the comparison of in vitro dissolution profiles. $J$ Pharm Biomed Anal. 1998;17(4-5):811-822. doi:10.1016/S0731-7085(98)00011-9

18. Afifi SA, Ahmadeen S. A comparative study for evaluation of different brands of metformin hydrochloride $500 \mathrm{mg}$ tablets marketed in Saudi Arabia. Life Sci J. 2012;9(4):4260-4266.

19. Hamdan II, Jaber AK. Pharmaceutical evaluation of metformin $\mathrm{HCl}$ products available in the Jordanian market. Jordan J Pharm Sci. 2010;3(22):1-7.

20. AlBratty M, Alhazmi HA, Alam MS, Alam MI, Javed SA, Alam N. Assessment of physicochemical properties and comparison of dissolution profiles of metformin hydrochloride tablets in Saudi Arabia. Dissolut Technol. 2020;27(1):36-44. doi:10.14227/DT270120P36 


\section{Publish your work in this journal}

Diabetes, Metabolic Syndrome and Obesity: Targets and Therapy is an international, peer-reviewed open-access journal committed to the rapid publication of the latest laboratory and clinical findings in the fields of diabetes, metabolic syndrome and obesity research. Original research, review, case reports, hypothesis formation, expert opinion and commentaries are all considered for publication. The manuscript management system is completely online and includes a very quick and fair peer-review system, which is all easy to use. Visit http://www.dovepress.com/testimonials.php to read real quotes from published authors.

Submit your manuscript here: https://www.dovepress.com/diabetes-metabolic-syndrome-and-obesity-targets-and-therapy-journal 